desapparecem tambem geralmente (Councilman, Golgi, Arnaud, Laveran).

Com respeito á pereirina, n'esse sentido, nada podemos affirmar, a não ser que, nos casos observados, o numero de crescentes se manteve mais ou menos constante.

Oppurtunamente diremos o que de um maior numero de casos, em cuja observação nos enpenhamos, se poder concluir.

Nota preliminar sobre seis casos de blastomycose ultimamente observados no hospital da Santa Casa de Misericordia de S. Paulo

Dr. Pedro Dias da Silva e Doutorando Ernesto de Souza Campos.

A's tres observações de blastomycose, publicadas nos numeros 5 e 6 desta Revista, juntamos mais seis casos observados no Hospital da Santa Casa de Misericordia, desta cidade, desde Agosto do anno passado até esta data, todos oriundos. do interior do Estado, con excepção de um, proveniente de Montevidéu.

Esses seis casos, por nós observados no curto periodo de um anno, em úm unico hospital, vêm por si provar a relativa frequencia da blastomycose em nosso meio e nos faz acreditar que é, certamente, elevado o numero de doentes atacados desta molestia, que têm passado despercebidos e considerados como portadores do outras entidades morbidas.

Todos esses casos, cujas observações publicamos, tinhąm o caracter de generalisação com lesões visceraes intensas e grande compromettimento do systema lymphatico, evidenciado pelas tumefacções das pleiades ganglionares de diversas regiões, onde proliferavam abundantissimos blastomycetos.

Em a nossa observação numero IV. notámos uma feição clinica toda especial, com o curioso phenomeno que, aliás, já foi uma vez observado por Corselli e Frisco em um caso de blastomycose, por esses autores publicado no Cbl. f. Backt. 1895 XVIII, qual o de uma ascite chylosa. No liquido chyloso encontrámos os blastomycetos, assim como, mais tarde (na necroscopia) na folha parietal do peritoneo. Esse mesmo doente era portador de uma pleurisia con dərrane, en cujo liquido tambem encontrámos parasitas. 
Em todos os casos, a lesão primitiva assestou-se sempre na bocca, principalmente nas amygdalas e isto, quando não no exame clinico, tem sido verificado nas necroscopias. A invasão do processo blastomyoetico, muito bem considerado, por Haberfeld, como granuloma maligno, se faz por intermedio do tecido lympho-adenoide, pelo qual se pode propagar a todos os recantos do organismo.

Apesar das variadas tentativas therapeuticas, que temos emprehendido, não tivemos nenhum caso feliz, não havendo (até agora), tratamento que dê resultado na blastomycose generalisada.

De facto, de todas as mycoses, é a blastomycose a unica que se tem mostrado rebəlde a qualquer tratanınts, sends que os poucos casos de cura, que têm sido registados, são de lesộes cutaneas ou de lesões muito iniciaes da mucosa oral.

Deste facto se infere a grande importancia da diagnose precoce da blastomycose, afim de evitar a generalisação que, uma vez produzida, traz comsigo o prognostico mais sombrio possivel, sendo, pois, de todo o interesse que, principalmente nas lesões granulomatosas do bucco-pharynge, sempre tenhamos o espirito prevenido quanto á possibilidade de uma blastomycose.

\section{OBSERVAÇ̃̃O I}

T. L., com 47 annos de idade, japonez, a narello, casado, colono, procedente de Villa Addolpho, entrado em 11 de Agosto de 1917, para um quarto particular da Santa Casa de Misericordia, sahido em 25 do mesmo mez, a pedido, por se considerar melhorado e novamente admittido a 18 de Outubro do mesmo anno na $3 .^{\mathrm{a}}$ Enfermaria de Clinica Medica (serviço do Professor Ovidio Pires de Campos).

Antes de entrar para o Hospital, consultou o Professor Walter Ha. berfeld, que depois de ter examinado o producto obtido pela raspagem de uma das amigdalas e o material retirado por punç̧ão de um ganglio lymphatico cervical, estabeleceu o diagnostico de blastomycose.

Não daremos a historia clinica, por isso que o seı resultado detalhado fará parte de uma publicação.

Apenas chamamos a attenção para o tratamento, que foi feito pelo neo-salvarsan, em doses successivas, repetidas e crescentes, sem o minimo resultado. Em seguida á primeira injecção, o doente sentiu-se - muito melhorado, a ponto de retirar-se do Hospital, facto esse perfeitamente explicavel, por isso que havia associação da syphilis á blastomycose, demonstrada pela reacção de Wassermann positiva e pelos dados obtidos pela historia pregressa.

Durante todo o tempo que esteve o doente no Hospital, consegui- 
mos fazer 10 injeç̧ões endovenosas de 914 , sem obter siquer o retardamento da infecçấo blastomycetica.

O doente falleceu e a necroscopia foi praticada pelo professor $\mathrm{Ha}-$ berfeld, no Instituto de anatomia pathologica da Faculdade de $\mathrm{Me}$ dicina e Cirurgia.

\section{OBSERVAÇÃO II}

F. C. C., com 60 annos de idade, hespanhol, casado, branco, colono, procedente de Quilombo e admittido a 17 de Agosto de 1917, no Hospital da Santa Casa de Misericordia, desta cidade, (1." Enfermaria de clinica medica).

\section{Antecedentes hereditarios.}

Paes, fallecidos em idade avançada, gozaram sempre excellente saude; quatro irmãos, dos quaes um apenas é vivo, mais idöso, sadio, e residente na Hespanha. Os seus irmãos falleceram, um aos trinta, outro aos cincoenta e oito e outro aos sessenta annos de idade.

Casado na Argelia, com uma franceza, della houve seis filhos robustos e sadios.

\section{Antecedentes pessoaes.}

Nega a existencia de qualquer.doença anterior.

\section{Historico.}

Dois mezes, mais ou menos, antes de entrar para o Hospital, notou na abobada palatina, na região correspondente aos dois ultimos mollares esquerdos, uma pequena ulceração indolor. Logo sobreveio grande fraqueza, cansaço ao menor esforço e gradualmente foi perdendo o appetite. Ligeiramente febril, incapacitado para o trabalho, começou a procurar allivio para o seu mal, empregando para isso varios me. dicamentos, inclusivé a applicação topica de nitrato de prata, sem obter nenhuma melhora. Aconselhado a operar-se, internou-se na Santa Casa de Misericordia. O Professor Celestino Bourroul e o Dr. Aristides Guimarães, examinando ao microscopio os fragmentos retirados, pela raspagem da ulceração, verificaram a existencia de numerosos blastomycetos, e estabeleceram o diagnostico de blastomycose, entregando-nos o caso para estudo, por nimia gentileza.

$\mathrm{O}$ doente relatou ainda que, cerca de 15 dias depois que observou a ulceração, formaram-se tumefacções em torno do pescoço, rebeldes ás applicações topicas de revulsivos os mais variados.

\section{Exame clinico.}

Individuo de estatura mediana, de compleição robusta, apresentando o tegumento externo, integro e normal.

Pela inspecção de região cervical, notavam-se grandes tumefacções, produzidas pelo infartamento dos ganglios regionaes, sobretudo na região correspondente aos gonios mandibulares de ambos os lados. 
Pelo palpar dos ganglios, verificava-se um augmento variavel de volume, desde o tamanho de uma ervilha, até o tamanho de um ovo de pomba; na região supra-hyoidéa, notava-se um ganglio do tamanho de uma noz grande, e, na região da nuca, outro do mesmo tamanho. As pleiades ganglionares das regiões axillares, inguinaes e cruraes, de ambos os lados, apresentavam notavel augmento de volume.

Signaes funccionaes.

Cephaléa, grande asthenia, anorexia, constipàção de ventre, dôres vagas em todo o ventre, dôr na região ulcerada da bocca (que no começo não sentia), suores pouco abundantes e febre de typo intermittente.

Signaes physicos.

Augmento de volume do baço e do figado, não muito accentuado. 1) Apparelho respiratorio.

Submacissez, respiração soprosa, estertores finos na base do pulmão direito; respiração vicariante no pulmão esquerdo; fremito thoraco-vocal normal em ambos os pulmões.

2) Apparelho circulatorio:

Accentuação da segunda bulha no fóco aortico; sessenta e oito pulsações por minuto.

3) Systema nervoso.

Reflexos patellares e achilleanos, ligeiramente exaggerados; todos os outros reflexos normaes.

EXAMES DE LABORATORIO.

1) Exame de sangue.

Primeiro exame.

a) Reacção de Wassermann: negativa.

b) Contagem total por millimetro cubico (hematimetro de ThomaZeiss) 20 de Agosto de 1917.

Hematias

2.980 .000

Leucocytos.

4.200

c) Formula leucocytaria.

Polymorpho nucleares neutrophilos

Polymorpho nucleares eosinophilos

Polymorpho nucleares basophilos

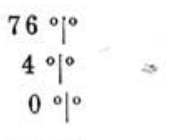

$\begin{array}{ll}\text { Lymphocytos } & \cdot \\ \text { Monocytos } & .\end{array}$ 
Foi encontrado um normoblasto.

d) Dosagem da hemoglobina: $\left.60^{\circ}\right|^{\circ}$ (Gowers-Sahli).

e) Indice hemoglobinico globular: 1,006.

Segundo exame, depois da primeira injecção de novarseno-benzol, , em 8 de Setembro de 1917 .

Contagem total (Thoma-Zeiss).

Hematias .

Leucocytos.

Terceiro exame de śangue, após mais duas injecções de neo-satvarsan, em 28 de. Setembro de 1917.

Contagem total (Thoma-Zeiss).

Hematias

Leucocytos.

2) Exame de fezes. Foi negativa a pesquiza de ovos de parasitas intestinaes.

3) Exame summario de urina. Em 26 de Agosto de 1917.

Reacção

Albumina

Glycose. .

Chloretos

Sedimento: crystaes octaedricos de oxalato de calcio e granulações de urato de sodio.

EXAME STOMATO-RHINO-LARINGOSCOPICO (Dr. Schmidt Sarmento), 27 de Agosto de 1917.

Lesões de pyorrhéa alveolar, nas proximidades das quaes, sobretudo na parte latero-inferior direita, encontra-se uma extensa zona rubra, semeada de pequeninos pontos hemorrhagicos. No palato duro, proximo aos ultimos mollares, existe uma ulceração de um centimetro e meio por meio centimetro, cuja parte central é granulosa e a peripherica, rubra, com pequeninas petechias, semelhantes ás primeiras.

Ambas as amygdalas estão lesadas, sobretudo a direita, na qual se vê, na parte superior, com propagação para o pilar posterior, que está edemaciado, uma ùlceração provida de pequeninas petechias.

Pela rhinoscopia posterior, verifica-se que ha lesões semelhantes no pharynge superior e que o larynge estã indemne.

\section{TRATAMENTO.}

Foram empregados o iodureto de sodio e o novarseno-benzol, sem resultado algum sob o ponto de vista de cura da infecção blastomycetica, retirando-se o doente do Hospital, a pedido, mais ou menos nas mesmas condições em que entrou. O neo-salvarsan determinou um 
augmento do numero de hematias, confórme se verifica pelas successivas numerações̀ globulares totaes.

\section{OBSERVAÇ̃̃O III}

J. S., com 47 annos de idade, portuguez, branco, casado, barbeiro, procedente da 5." Parada, nesta capital, admittido a 23 de Outubro de 1917, no Hospital da Santa Casa de Misericordia, desta cidade, recolhendo-se ạo serviço clinico da terceira enfermaria de clinica medica (Dr. Ovidio Pires de Campos) e fallecido no dia 3 de Dezembro do mesmo anno.

\section{Antecedentes hereditarios.}

Paes, fallecidos; tres irmãos, mais velhos, sädios e residentes em Portugal; um unico filho, com 20 annos de idade, actualnente na Africa.

\section{Antecedentes pessoaes.}

Sarampo; contrahiu a infecção paludica, ha cerca de 15 annos, quando residia em Portugal; nunca soffreu de molestias venereas $e$ já teve ha muito tempo uma affeç̧ão pulmonar. E' portador de' solitaria (toenia saginata).

\section{Historico.}

Esteve durante tres annos no Brasil, residindo em Rio Preto e São João da Bôa Vista, regressando para Portugal, onde permaneceu um anno, de lá seguindo para Montevidéu. Estabeleceu residencia naquella cidade, durante cinco annos, e, ha cerca de oito mezes, voltou ao Brasil, achando-se já affectado da molestia actual.

Ha cerca de nove mezes (em Montevidéu) sentiu dores na garganta, tornando-se quasi aphonico, apesar de todos os tratamentos que empregou para se vêr livre de tão incommodo mal.

Dé quatro mezes para cá, notou uma tumefacção no pescoço (região do esterno-cleido-mastoideu) e depois outras que se foram multiplicando.

Mais tarde observou que outros intumescimentos appareciam, nas regiões axillares, inguinaes e cruraes de ambos os lados.

Quando esteve no Brasil pela primeira vez, trabalhou como colono em varias fazendas, e, em Montevidéu, empregou-se em uma Estrada de Ferro, exercendo a funçãa de foguista. Sentindo-se muito fraco, não mais poude trabalhar depois que sahiu de Montevidéu.

Alimenta-se muito mal, não só por falta de appetite, como tambem por causa das dores produzidas pela deglutição.

\section{Exame geral.}

Individuo de compleição robusta, nada apresentando de anormal no tegumento externo, na occasião do primeiro exame. Mais tarde, 
alguns ganglios do pescoço, que primitivamente eram duros, tornaram-se molles, rompendo-se a pelle e dando sahtda para o exterior a uma substancia puriforme.

Apresenta extensa adenopathia, comprehendendo as pleiades ganglionares cervical, axillares, inguinaes e cruraes.

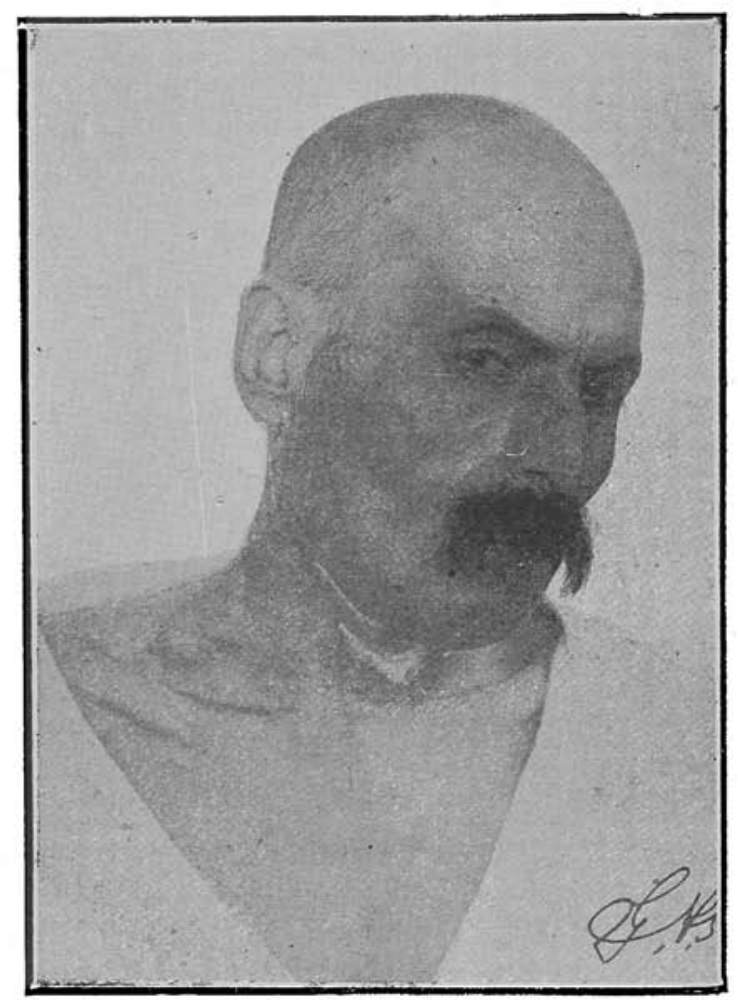

Caso III

EXAME STOMATO-LARINGOSCOPICO (Dr. Schmidt Sarmento).

Observa-se na parte interna da gengiva, proximo ao terceiro mollar esquerdo, uma ulceração apresentando as dimensões de $12 \times 10$ millimetros, ligeiramente granulosa, com minusculos pontos hemorrhagicos. Ha falta de dois caninos e dois insisivos do lado direito. Na região do palato molle, eneontramos de diante para traz, no seu terço anterior uma ulceração semelhante a que foi primeiro descripta, e, nos dois terços posteriores, uma lesão que faz lembrar o herpes. Na. região correspondente aos dentes cahidos, do lado direito, ha uma. 
grande ulceração semelhante ás já descriptas e que se extende até o palato duro.

Identicas lesões são encontradas nas amygdalas, na epig̉lotte, nas cordas vocaes superiores e inferiores e na vallecula e suas pregas, quer mediana quer lateraes.

A região sub-glottica parece illesa.

\section{TRATAMENTO.}

Empregámos o iodureto de sodio, intensamente e por via endovenosa, depois o salycilato de sodio e, finalmente, o cyanureto de mercurio tambem por via endovenosa, sem obter resultado algum.

$O$ doente falleceu subitamente no dia 3 de Dezembro, sendo o seu cadaver enviado ao laboratorio de Anatomia Pathologica da Faculdade de Medicina, onde foi autopsiado.

\section{EXAMES DE LABORATORIO.}

1) Exame de sangue.

a) Contagem total por millimetro cubico (hematimetro de ThomaZeiss).

Hematias

1.448 .000

Leucocytos.

4.000

b) Contagem especifica.

Polymorpho nucleares neutrophilos.

Polymorpho nucleares eosinophilos

Polymorpho nucleares basophilos

Lymphocytos

Monocytos.

c) Dosagem da hemoglobina (Gower-Sahli)

d) Valôr hemoglobinico globular.

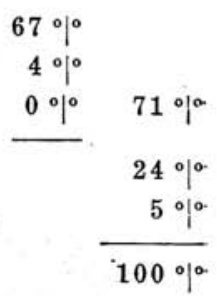

e) Viscosidade sanguinea (App. de Hess.) .

f) Reacção de Wassermann

2) Exame de fezes. Flagellados e anneis de toenia.

3) Exame de escarro. Negativo em relação á existencia de bacillos de Koch.

4) Exame de urina (Dr. Geraldo Paula Souza).

Quantidade remettida

Volume 24 horas

Côr . .

Aspecto .
450 c. c.

450 c. c.

amarello pal.

turvo 
Consistencia

acquosa

Cheiro

Deposito

ammoniacal

Densidade

Reacção tournesol .

abund. e esb.

Exame microscopico.

1,021

alcalina

grãos phos. am.

Elementos pathologicos encontrados: pigmentos sanguineos e biliares, pequena quantidalde de albumina.

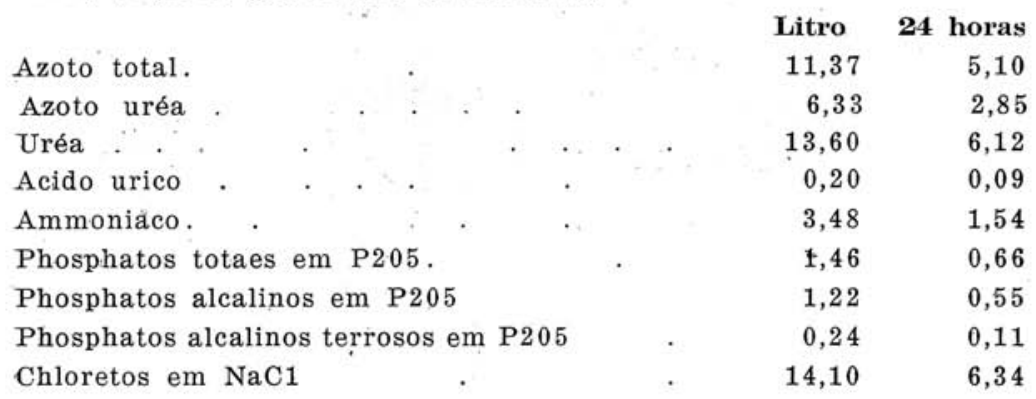

EXAME CULTURAL. O producto obtido pela puncção de um ganglio cervical, semeado em meio de Sabouraud, deu, no fim de $2 \theta$ dias, culturas que se acham agóra desenvolvidas.

o exame microscopico do mesmo material demonstrou a existencia de numerosos blastomycetos.

\section{OBSERVAÇÃO IV}

PERITONite BLASTOMYCETICA - Communicação feita á Sociedade de Medicina e Cirurgia de S. Paulo, em sessão de $10^{\circ}$ de Maio de 1918 e publicada no.n. ${ }^{\circ} 3$ do Boletim da mesma sociedade.

T. S., com 40 annos de idade, japonez, casado, colono, procedente desta capital (rua Conde de Sarzedas) e admittido a 18 de Fevereiro do corrente anno, no Hospital Central da.Santa Casa de Misericordia: desta cidade.

Antecedentes hereditarios.

Paes, fallecidos; quatro irmãos e quatro filhos sadios, residenteś no Japão.

Antecedentes pessoaes.

Ha quinze annos teve adẻnite inguinal dupla suppurada e ha cerca de vinté annos, gonorrhéa. Nada mais informou de importancia.

Historico.

$\mathrm{Ha}$ seis annos veio para o Brasil, fixando residencia durante dois annos nesta capitaI; depois residiu durante um anno em Ribeirão 


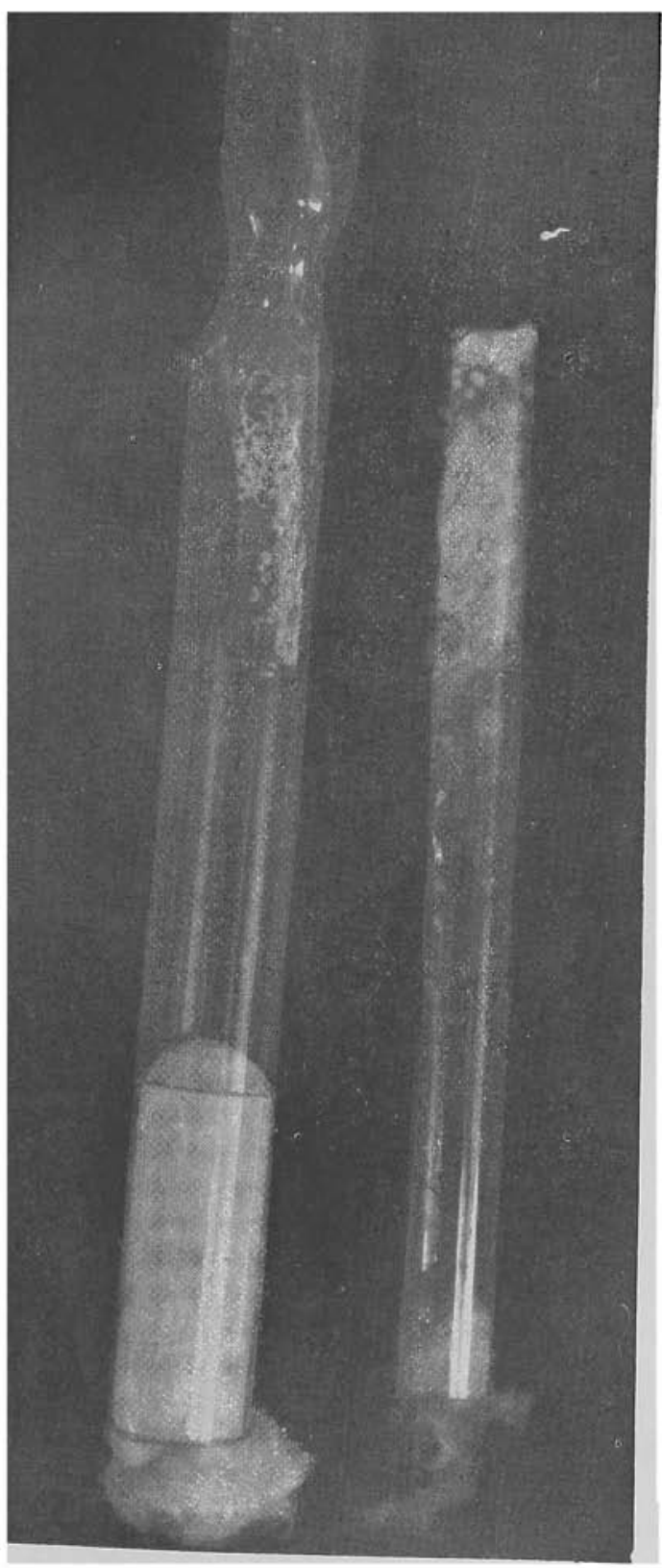



Preto, dois na estação de Rechan (E. F. Sorocabana) e ha cerca d€ um anno voltou a residir em São Paulo.

Em Novembro de 1917, começou a sentir-se fraco, inappetente e notou que emmagrecia consideravelmente. Em Janeiro do corrento anno, notou que se lhe formava uma tumefacção na altura do gonio mandibular direito; mais tarde, varias outras tumefacções appareciam dissimenadas pelo pescoço, axillas, regiões inguinaes e cruraes. Em meados de Fevereiro o seu ventre começou a crescer, tornando-sè gradativamente mais pesado e tenso.

\section{Exame clinico.}

Individuo de compleição franzina, extraordinariamente emmagrecido, contrastando essa magreza com o enorme desenvolvimento do ventre, que apresentava o perfeito typo de ventre de batrachio. Nas regiões acima citadas, chamavam a attenção as saliəncias produzidas pela tumefacção dos ganglios. Na região crural esquerda, assim como ao nivel do ramo mandibular direito, os ganglios, pelo palpar, davam a sensação de fluctuação. Era perfeita a intəgriłade do tegumento externo.

Tinha febre com typo intermittente, grande asthenia a ponto de não poder caminhar e vomitava incessantemente.

Para o lado do apparelho respiratorio, apresentava os apices pulmonares claṛos á percussão, baร๖ esłuerda sub nasį̧a, base direita maciça com abolição do fremito thoraco-vocal e da respiração; respiração soprosa nos dois pulmõez e aspəra nว apiis dirəitว; typo respiratorio costal superior com 16 respirações por minuto. 'A punç̧ão exploradora da base direita deu um liquido de aspecto chyloso, mais ou menos côr de opala.

No apparelho cardio-vascular o coração estava nos limites normars, as bulhas eram puras e pouco audiveis e o pulso radial fraco orçava por 104 pulsações.

Quanto ao apparelho digestivo, assignalavam-se prisão de ventre, anorexia e vomitos incoerciveis. Figado e baço nos límites normaes. Systema nervoso e demais apparelhos, normaes.

No exame estomato-rhino-laringoscopico, procedido pelo dr. SCHMIDT SARMENTO, foi verificada a existencia de ulcerações mais où menos superficiaes no vestibulo da bocca, sobretudo na gengiva correspondente á arcada dentaria inferior, do lads esłuerdo, estendendo-se ưm pouco até á porção interna da mucosa gəngival. Em al. guns pontos, a lesão, mais profunda, destruiu a gengiva, deixanro a descoberto as raizes dos dentes, lembrando as ulceraç̃̃es produzidas pela pyorrhéa alveolar. Outras lesões, c.om o mesmos caracteristicos. isto é, semeadas de pequeninos pontos henorrhagicos, foram nota- 
das no palato molle e nas amygdalas, que estavam quasi destruidas. $\mathrm{Na}$ rhino-laryngoscopia nada de anormal foi observado.

O ventre, como já fizemos notar, achava-se muito desenvolvido e com a parede muito tensa; media de circumferencia, ao nivel do umbigo, 88 centimetros e ao nivel da meia altura entre o umbigo e a symphise pubiana, 83 centimetros. Com o fim de alliviar um pouco o doente, procedemos a diversas paracênteses que déram sempre $\mathrm{um}$ liquido leitoso, ligeiramente esverdinhado, semelhante ao retirado na punç̧ão pleural.

O exame microscopico do liquido puriforme retirado por punç̧ão de um ganglio crural, revelou a presença de numerosissimos blastomycetos e decidiu logo do diagnostico de blastomycose ganglionar com propagação para as visceras, diagnostico esse que, aliás, já suspeitavamos e procuravamos fazer, não só porque nos impressionasse a particularidade do quadro clinico que o doente apresentava, como tambem porque haviam sido feitas pesquizas, negativas quanto á bacillose e á syphilis, que estavam por assim dizer eliminadas.

Como complemento á nossa observação, outros exames de laboratorio foram feitos, cujos resultados damos a seguir:

a) EXAME DE SANGUE:

1) Contagem especifica:

Polymorphos nucleares neutrophilos. Polymorphos nucleares eosinophilos. Polymorphos nucleares basophilos Lymphocytos.

Monocytos .

2) Contagem total:

$$
\begin{array}{r}
82,25 \%^{\alpha} \\
1,00 \% \\
0,25 \% \\
10,00 \% \\
6,50 \% \\
\hline 100,00
\end{array}
$$

4.500 .000

4.600

70 잉

0,78

negativa

5) Reacção de Wassermann .

b) Exames de fezes: negativo em relação á existencia de ovos de parasitas intestinaes.

c) Exame de escarro: negativo em relação á presença de bacillos de Koch.

d) Exame do liquido ascitico:

1) Exame cytologico: Cellulas endotheliaes e leucocytos, cuja contagem especifica vae abaixo discriminada: 
Polymorphos nucleares neutrophilos . $69,00 \%$ 이응

Polymorpho nucleares eosinophilos

Polymorphos nucleares basophilos.

$0,00 \%$

Lymphocytos

$25,\left.00^{\circ}\right|^{\circ}$

Monocytos

2) Pesquiza de bacillos de Koch: negativa.

3) Exame chimico: O exame chimico qualitativo demonstrou a presença dos seguintes elementos: albumina, acido-albuminas, albumoses, peptonas, syntonina e gordura.

4) Exame biologico: A reacção do desvio do complemento, sendo empregado como antigeno o liquido ascitico e como anti-corpo o serum sanguineo, deu resultado negativo.

5) Reacção de Rivalta: positiva.

e) Exames culturaes: Foi semeado o liquido puriforme obtido por puncção de um ganglio, em meio de prova de Sabouraud, em batata e em cenoura, Cểrca de um mez depois, começaram a apparecer culturas que se estão desenvolvendo na batata e na gelose de Sabouraud.

f) Inocullações: Foram inoculados dois cobaios e quatro ratos com o liquido ascitico e com o liquido puriforme. Ainda não ha resultado.

g) Intra-dermo-reacção: A injecção intra-dermica de liquido ascitico filtrado em vela de Chamberland, nenhuma reacção produziu no doente.

h) EXAME DE URINA:

1) Diazo-reacção de Ehrlich: francamente positiva.

2) Reaç̧ão de Moritz-Weisz: positiva.

3) Exame chimico e cytologico (Feito pelo prof. Paula Souza):

Volume em 24 horas . . . 370 c. c.

Côr

Aspecto.

Consistencia

Cheiro . .

Deposito

Densidade $\left(15^{\circ}\right)$

avermelhada

Reacção

bem turvo

acquosa

sui generis

abundante

1.023

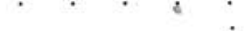

N. total. . . . . 16.35

Uréa. . . 33.80

Acido urico . . . 0.37

Ammoniaco . . . . . $\quad 1.20$ 
Phosphatos totaes em P205. . 6.16

Phosphatos alealinos.

4.62

Phosphatos terrosos

1.54

Chlorêtos em NaC1.

9.30

Elementos pathologicos — Traços de albumina e acidos biliares.

Elementos microscopicos - Cellulas epitheliaes e crystaes de oxalato de calcio.

Como tratamento foi empregado o iodureto de potassio, sem nenhum resultado. O prof. Pinheiro Cintra empregou, pela via endovenosa, o acido lactico e, em injecções intra^peritoneaes, uma solução iodo-iodurada, tambem sem nenhum resultado.

$O$ doente veiu a fallecer no dia 16 de Abril.

O cadaver foi necroscopiado no Instituto de Anatomia Pathologica da Faculdade de Medicina, pelo prof. Harberfeld e dr. Carmo Lordy, com o seguinte resultado:

Relatorio da Necroscopia - Cadaver com 1,58 cms. de comprimento, muito emmagrecido. Cicatrizes ao longo do bordo inferior mandibular direito. Inchação ganglionar generalisada (cervical, axillar, inguinal, epitrochleana, crural, mesenterica), com ganglios variando de tamanho - desđe um grão de foijă até o de una noz. Esses ganglios tinham a côr acinzentada, uns, e amarellada, outros, e a consistencia augmentada em alguns e pastosa noutros. Ao córte, os ganglios se mostravam humidos, alguns amarellados e outros de côr cinzenta.

$\mathrm{Na}$ bocca, os dentes molares e premolares tinham inteiramente expostas as raizes, faltando a parede alveolar e a gengiva, que se achavam transformadas em tecido duro,' de côr parda e de superficie irregular. No logar das duas amygdalas palatinas encontravam-se duas perdas de substancia do tamanho de um grão de feijão, de bordos irregulares, de fundo espesso e de côr amarello-cinzenta. As mucôsas pharyngeana e laryngeana estavam muito anemicas. Cerebro pésando 1.600 grms., com edema-agúdo. Pulmões com anemia dos lobos superiores e hypostase dos inferiores. Coração com atrophia fosca. Figado de volume diminuido e pesando 1230 grms.; capsula de Glisson muito espessada e com intima adherencia fibrosa ao diaphragma, por tres pontos. Os córtes de figado mostram a estructura desapparecida, a côr castanha com pontos amarellados, e sulcos finos e profundos tambem amarellados; pouco sangue e consistencia augmentada. Baço com 105 grms., de consistencia augmentada e com a capsula cheia de dobras; ao córte, via-se a superficie avermelhada, com pontos acinzentados; quasi não havia polpa vermelha aว esfregaço e estava muito desenvolvido o estroma. Rins com inchação turva e dege- 
neração gordurosa. Peritonite: nas folhas parietal e visceral do peritoneo notava-se uma camada de substancia facilmente destacavel, de côr amarello-esverdinhada, estando por baixo dessa camada a superficie peritoneal lisa e com os vasos injectados. Na cavidade peritoneal havia liquido ascitico (4 litros mais ou menos), de côr amarello-esverdinhada e turvo. No intestino delgado (ileon) foram notadas duas perdas de substancia, de bordos irregulares e do tamanho de um feijão.

Pelo exame histo-pathologico de um córte do baço, foram constatadas lesões iniciaes de invasão blastomycetica. No producto da raspagem do folheto parietal do peritoneo, encontrámos numerosissimos. blastomycetos.

\section{OBSERVAÇÃO V}

T. T., com 39 annos de idade, japonez, casado, procedente de Itatinga, admittido em 9 de Julho de 1918, no Hospital da Santa. Casa de Misericordia e recolhido ao serviço do professor Alves de Lima (2. ${ }^{a}$ enfermaria de cirurgia); transferido em 17 do mesmo mez para o serviço do professor Ovidio Pires de Campos (3. ${ }^{a}$ Enfermaria de clinica medica).

No serviço do professor Alves de Lima, o exame do liquido puriforme, retirado de uma ulceração, demonstrou a existencia de blastomycetos em quantidade.

Transferido para a $3 .^{\mathrm{a}}$ Enfermaria de clinica medica, ahi fizemos. o exame de sangue, em 17 de Julho de 1918.

\section{Contågem total:}

Hematias. . . . . 2.232.000 Leucocytos . . . . . . $\quad 9 \% 600$

Contagem especifica:

Polymorpho nucleares neutrophilos. . . $\left.86^{\circ}\right|^{\circ}$

Polymorpho nucleares eosinophilos . . . $\quad 0^{\circ} 0^{\circ}$

Polymorpho nucleares basophilos. . $0 \%$

Lymphocytos. $\quad$. $\quad 12 \%$

Monocytos . . . 2 $2 \%$

100

Dosagem de hemoglobina . . . $33{ }^{\circ}$

Indice hemoglobinico globular . . . 0,74

. Imagem de Arneth, desviada para a esquerda.

Indice numerico de Wolf 155,5 .

O doente, que vinha soffrendo ha dez mezes, sendo operado duas vezes em uma cidade do interior do Estado, falleceu em 18 de Julho. 
do corrente anno e a necroscopia foi praticada no Instituto de Anatomia pathologica, da Faculdade de Medicina e Cirurgia.

A sementeira, em meio de Sabouraud, deu culturas.

\section{OBSERVAÇ̃̃O VI}

J. J. S., com 23 annos de idade, brasileiro, natural de Minas, casado, pardo, lavrador, domiciliado em Ibarra e admittido na primeira enfermaria de clinica medica do Hospital da Santa Casa de Misericordia, desta capital.

o Dr. Aristides Guimarães, gentilmente, chamou a nossa attenção sobre o doente, portador de tumefacções ganglionares cervicaes, axillares, inguinaes e apresentando augmento de volume do baço, verificavel á percussão.

No liquido retirado por punçãa de ụm ganglio cervical, constatámos a presença de numerosos blastomycetos.

Antecedentes familiares.

Sem importancia.

Antecedentes pessoaes:

Coqueluche - Gonorrhéa. Ha quatro annos, teve adenite inguinat direita suppurada e ha dois annos, impaludismo.

\section{Molestia actual:}

Ha cinco mezes, notou que se formava uma tumefacção no gonio mandibular esquerdo, e, mais tarde, que outrás tumefacções se formavam ao longo dos dois ramos do maxillar inferior. Em uma cidade do interior, extirparam-lhe os ganglios logo depois reapparecendo outros, ao mesmo templo que appareciam outras tumefações semelhantes nas regiốes axillares, inguinaes e cruraes. Sentindo grande asthenia e 1mpossibilitado para o trabalho, resolveu recolher-se ao Hospital. Refere que, no principio da doença, tinha suores abundantes. Não sente difficuldade na deglutição.

\section{Exame somatico:}

Individuo de compleição robusta, estatura mediana, apresentando no tegumento externo algumas cicatrizes antigas e uma pequena fistula na parte lateral esquerda e inferior da região cervical, correspondente á incisão operatoria.

Ganglios cervicaes, supra-cláviculares (até o tamanho de uma amendoa), axillares (até o tamanho de um ovo de gallinha) inguinaes esquerdos têm, em conjuncto, o tamanho de uma laranja. Gannaes esquerdo têm, em conjuncto, o tamanho de uma laranja. Ganglios epitrochleanos, augmentados de volume. Edema muito accentuado do membro inferior esquerdo. 
Apparelho respiratorio:

Normal. Typo respiratorio abdominal. Vinte respirações por m1nuto.

Apparelho cardio-vascular:

Ligeiro reforço da segunda bulha. Iotus cordis no $5 .^{\circ}$ espaço intercostal esquerdo, um pouco para dentro da linha mamillar. Oitenta pulsações por minuto.

Apparelho digestivo e annexos:

Nenhuma perturbação, para o lado do tubo digestivo. Figado com onze centimetros na linha mamillar. Baço palpavel.

Apparelho genito urinario:

Normal.

Systema nervoso:

Reflexos patellares, achillianos, bicipitaes, tricipitaes, radiaes, do omoplata, normaes.

Reflexos cutaneos abdominaes e cremasterinos normaes.

Apparelho da visão:

Reflexos á luz e á accommodação, normaes. Fundo de olho, normal.

Apparelho da audição:

Normal.

Exame de fezes: ovos de Nécator.

Exame de urina:

Quantidade remettida, $3.300 \mathrm{cc}$.

Côr - Amarello pallido.

Aspecto - Ligeiramente turvo.

Consistencia - Acquosa.

Cheiro - Suis generis.

Deposito - Minimo.

Densidade - 1,004 .

Reacção tournesol - Fracamente acida.

Exame microscopico - Raras cellulas epitheliaes ch?

Albumina - Traços minimos

Acidez, om $\mathbf{H C l}-0,18$.

Azoto total - 4,00.

Uréa - 260 .

Acido urico $-0,57$.

Ammoniaco -264 .

Chloretos em NaCl $-3,90$.

EXAME DE SANGUE:

A) Contagem total:

Hematias

3.760 .000

Globulos brancos :

8. 200 
B) Contagem especifica:

Polymorphos nucleares neutrophilos $76,0^{\circ} \circ p^{\circ}$

Polymorpho nucleares eosinophilos . .. .

4,5 잉.

$0 \%$

Polymorphos nucleares basophilos...

Lymphocytos

Monocytos.

Imagem de Arneth, desviada para a esquerda.

Indice numerico de Wolf - 184,5.

C - Hemoglobina $-\left.31^{\circ}\right|^{\circ}$.

D - Indice hemoglibinico globular - 0,439.

$\mathrm{E}$ - Reacção de Wassermann - negativa.

Evolução - Apesar do tratamento empregado, o seu estado se tem aggravado, augmentando extraordinariamente as tumefacções ganglionares.

O tumor ganglionar inguinal esquerdo, veio a furo, sahindo cerca de um litro de pus.

o edema generalisou-se e a fraqueza accentuou-se, a ponto do doente não mais poder deixar o leito. Anorexia completa.

Na parte média do esterno, formou-se uma elevação que augmenta. gradualmente de volume.

Febre - Vide quadro annexo.

Tratamento - Iodureto de sodio, azul de methylenio, sôro. de cavallo anti-fermento.

Resultado - Absolutamente negativo.

Pesquizas de blastomycetos na urina e no escarro - negativas.

\section{Myospasia}

Dr. Campos Seabra.

Uma nossa cliente, de 12 annos de idade, desnutrida, nervosa, de mediocre intelligencia, descendente de pae alcoolico-syphilico e de mâe hysterica, rebento unico sobrevivente de um connubio de 16 annos, unico remanescente de um espolio consanguineo de abortos o nati-mortos, é, de quando em quando, presa, em pleno repouso, de contracções involuntarias generalisadas.

No inicio da molestia, o quadro morbido reduzia-se á tremores paroxysticos, fugazes e parciaes, compromettendo alguns musculos da coxa e da perna. 